\title{
O PAPEL DA EDUCAÇÃO NA FORMAÇÃ̃O DO CIDADÃO: INCLUSÃO SOCIAL EM SÃO PAULO
}

\author{
Francisco José Pires ${ }^{1}$
}

\section{RESUMO}

Ao longo desta pesquisa, compartilhei com educandos, homens e mulheres, trabalhadores paulistanos, suas alegrias diárias, seus sofrimentos, a luta pela sobrevivência, enfim suas vidas. Como seres históricos, eles dispunham de experiência e da capacidade de, intervindo no espaço, conhecer este espaço, cujo trabalho cotidiano consiste em procurar seu destino pelas trilhas da cidade de São Paulo. O presente trabalho tem como tema o papel da educação na formação do indivíduo para a Inclusão Social em São Paulo a partir de 1980. Procura-se analisar a questão das condições de trabalho em que vive a população de São Paulo e o papel da educação nesse contexto, uma vez que pode inevitavelmente definir o tipo de cidadão que ocupa os espaços dessa Metrópole Sul-Americana, na qual pobreza e riqueza andam de mãos dadas numa promiscuidade dificilmente vivenciada na história da humanidade. Esse paradoxo provém da constatação de que as questões das políticas educacionais e do desemprego generalizado se converteram, na década de 1990, em problemas emergentes carentes de soluções por parte do poder público. Nesse sentido, entender o papel da educação nesse contexto pode contribuir para o debate desta problemática, assim como para a avaliação e formulação de alternativas possíveis para o enfrentamento da educação em São Paulo, face às exigências da atualidade.

Palavras-chave: Educação. Formação do Cidadão. Inclusão Social.

\section{INTRODUÇÃO}

O presente trabalho tem como tema o papel da educação na formação do cidadão para a Inclusão Social em São Paulo a partir de 1980. Procura-se analisar a questão das condições de trabalho em que vive os atores sociais e o papel da educação nesse contexto, que vai inevitavelmente definir o tipo de cidadão que ocupa os espaços dessa Metrópole Sul-Americana.

As transformações estruturais do Estado, implementadas no Brasil, não deram conta de resolver o problema a curto e médio prazo. Nesse sentido, entender o papel da educação nesse contexto pode contribuir para o debate desta problemática, assim como para a avaliação e formulação de alternativas possíveis para o enfrentamento da crise da educação no Brasil, especialmente em São Paulo, objeto desse estudo, face às exigências atuais.

No bojo das discussões e reflexões que foram provocadas com a implantação da nova Lei de Diretrizes e Bases da Educação Nacional - Lei n. 9394/96, observa-se que já no Título II "Dos Princípios e Fins da Educação Nacional" em seu artigo 2. ${ }^{\circ}$ aqui reproduzido: "A educação, dever da família e do Estado, inspirada nos princípios de liberdade e nos ideais de solidariedade humana, tem por finalidade o pleno desenvolvimento do educando, seu preparo para o exercício

\footnotetext{
Doutor e Mestre em Integração da América Latina, Jornalista, Geógrafo e Pedagogo. E-mail: fco.pires@hotmail.com.
} 
da cidadania e sua qualificação para o trabalho", procura-se garantir uma educação voltada ao exercício pleno da cidadania e à preparação para o mundo do trabalho. No entanto, as pesquisas apontam que com um processo de globalização desigual, a incerteza global torna-se cada vez maior pela ausência de processos educativos consistentes que possam atender à demanda educacional e profissional do mundo atual.

Neste cenário, faz-se necessário o entendimento de que a produtividade do trabalhador não é mais avaliada pela sua mestria numa determinada tarefa, mas sim pela sua habilidade de aprender, transferir e aplicar o aprendido, num contexto de aprendizagem contínua. A competência do trabalhador, na chamada "sociedade Pós-industrial", passa a ser determinada pela sua capacidade de relacionar e de integrar conhecimento e trabalho. Este trabalho pretende ampliar o estudo nesta área, dada a importância e complexidade de que se reveste.

Naturalmente, as considerações colocadas ao longo do estudo terão seu conteúdo referenciado ao contexto latino-americano, especialmente a região metropolitana de São Paulo, no que se refere à formação do cidadão para inclusão social, porém, trata-se de um esforço de compreensão de uma temática posta para discussão e, em nenhum momento tem-se a pretensão de esgotar o assunto, dada a abrangência e complexidade da questão.

Procura-se, entretanto, apresentar alguns resultados da pesquisa realizada, cientes de que, estes, estão sujeitos a omissões ou até mesmo interpretações redundantes, tendo em vista a compreensão parcial das leituras que se fizeram necessárias durante o processo de investigação. Em consequência, avançar na pesquisa sobre a formação do cidadão para a inclusão social em São Paulo significa aprofundar a compreensão das transformações que perpassa o espaço da cidade, o que equivale a um melhor entendimento da organização da sociedade e de suas estruturas no passado e no presente.

Delimitou-se esse período porque foi a partir de 1980 do século XX, com o processo de reabertura política no Brasil e, principalmente nos anos 90, com a reestruturação econômica, que São Paulo passou a conviver mais intensamente com as dificuldades enfrentadas pelo cidadão no que diz respeito a sua formação e ao mercado de trabalho.

\section{ALGUMAS CONSIDERAÇÕES SOBRE O PROBLEMA}

O desemprego em massa que se faz presente no Brasil, na última década do século XX, torna-se um problema emergente, ou seja, o grande desafio enfrentado pelo país é preparar o cidadão para o mercado de trabalho, e, ao mesmo tempo, criar postos de trabalho para atender a demanda de mão-de-obra, tarefa que não tem sido fácil para os países de economia dependente. 
Nesse contexto, identifica-se na Região Metropolitana de São Paulo, por um lado, uma crise sem precedente na educação, face as políticas governamentais implementadas pelo Estado, atendendo às exigências das Agências Internacionais de Financiamento como, o Banco Mundial e o BIRD ${ }^{2}$. Por outro lado, uma crise do emprego caracterizada, basicamente, pela diminuição assustadora do emprego formal, aumento do emprego informal, precarização das relações de trabalho, perda do poder de compra dos trabalhadores e, consequentemente, aumento das desigualdades sociais.

A reflexão que nos ocupa constrói-se a partir de um trabalho de recopilação, revisão bibliográfica e análise de dados, que toma dimensão à medida que se considera as políticas públicas implementadas pelo governo brasileiro no sentido de atender às demandas de formação de mão-de-obra, possibilitando assim a inclusão social.

A realização desta pesquisa compreende a superação de algumas etapas no processo de investigação científica. Para análise das políticas públicas de formação do cidadão e o papel da educação no espaço estudado, foram elencadas algumas variáveis com o intuito de se obter o maior número de informações que demonstrem com fidedignidade a realidade estudada.

O crescimento acelerado das cidades propiciou sérios problemas sociais, como: educação, desemprego, transporte coletivo sucateado, moradia, saúde, lazer, entre outros. Visto que não ocorreram nestes setores alterações estruturais significativas que atendessem às demandas e pressões sociais.

Um ponto nevrálgico a ser pensado é o diagnóstico das causas de fracasso escolar e o papel da educação nesse processo, pois ao mesmo tempo em que se convive com um desemprego em massa e com novas exigências em relação ao perfil do trabalhador, não se tem dados significativos sobre uma formação permanente efetiva para atender a demanda de mão-de-obra nos moldes que o mercado exige.

Trata-se de uma questão crucial, pois é possível presumir que a maior parte das políticas de formação tem um diagnóstico das causas em suas bases, e isso é o que determina a direção e o objetivo dessas políticas.

\section{REFLEXÕES ACERCA DAS HIPÓTESES}

Ao se estudar as políticas públicas de formação do cidadão para a inclusão social implementadas em São Paulo, como aporte para viabilizar o processo de urbanização de seus

\footnotetext{
${ }^{2}$ Banco Internacional para Reconstrução e Desenvolvimento.
} 
espaços, vale discutir as questões emergentes que deram origem aos grandes movimentos sociais urbanos.

A reestruturação econômica implementada no Brasil sob a ótica do neoliberalismo com a diminuição do tamanho do Estado e consequentemente de sua intervenção, na economia, nos equipamentos públicos e na sociedade, suscita um novo entendimento da eficiência e eficácia do estado em relação às décadas anteriores.

Nesse sentido, busca-se discutir ao longo da pesquisa algumas questões, tais como:

- Que medidas poderiam desencadear um processo de recuperação da Educação Básica (gestão, professor, métodos, recursos financeiros, recursos físicos, etc.);

- Qual o papel do Estado e da educação na formação do cidadão para o mercado de trabalho?

- Qual a função social da escola?

- Como perceber no processo de modernização aspectos das relações sociais capitalistas e seu impacto no conjunto da sociedade?

Essas questões abrem uma perspectiva de análise capaz de se fazer uma leitura próxima da realidade, no sentido de contribuir na compreensão de como se deu a intervenção do Estado a partir dos anos 80 no Brasil, reelaborando aspectos de própria vida social. A relação políticas públicas de geração de empregos e educação é o paradigma com o qual se espera responder tais indagações.

\section{O PAPEL DA EDUCAÇÃO NA FORMAÇÃO DO CIDADÃO PARA INCLUSÃO SOCIAL EM SÃO PAULO A PÁRTIR DE 1980}

O início da década de 1990 representa o começo de um novo processo para o desenvolvimento socioeconômico brasileiro. Haver alcançado a Institucionalidade democrática significou a evolução política do País a partir de 1980. Acerca das transformações sofridas no final do século XX, Dourado (2001) afirma:

$\mathrm{O}$ mundo do trabalho e da produção expressa às significativas transformações, originadas pelo incremento das relações sociais capitalistas e traduzidas, nesta virada de século, pelo expressivo avanço tecnológico e pela globalização do capital e do trabalho. Essas transformações societárias redimensionam o papel da educação e da escola (DOURADO, 2001, p. 49).

$\mathrm{O}$ autor argumenta que as agências educacionais passam a ser vislumbradas como um dos elos de socialização dos conhecimentos técnico-científicos historicamente produzidos pelo desenvolvimento de habilidades, capacidades e competências sociais requeridas, predominantemente, em sintonia com o setor produtivo, no qual "educação formal e a qualificação 
formal são situados como elementos de competitividade, reestruturação produtiva e da “empregabilidade" (FRIGOTTO, 1998, p.15). Nesse sentido, o papel da educação tornou-se fundamental, como premissa para garantir o projeto oficial de desenvolvimento implementado pelo governo brasileiro.

Desta forma, a década de 1990 caracterizou-se pela introdução de reformas educacionais no Brasil, sobretudo no que se refere ao combate ao analfabetismo, assim como a democratização do acesso e permanência escolar. Nesta fase, a escola democratizou o acesso, porém não garantiu a permanência dos alunos, uma vez que as condições oferecidas para essa escolarização não foram alteradas/modificadas, refletindo diretamente na baixa qualidade de ensino. Parece aplicar-se, aqui, a afirmação de Oliveira (2001) com relação a essa questão:

\begin{abstract}
Assim, a década de 1990 será marcada pela tentativa de reformas educacionais que busquem, sobretudo, estender a educação a toda população e erradicar o analfabetismo, porém contaminadas de uma compreensão restritiva do termo educação básica. Ao lado das exigências de universalização do acesso à educação, procurava-se combinar medidas de racionalidade técnica para a gestão dos recursos públicos aplicados no setor. A combinação penosa desses dois fatores resultou na maior oferta de serviços educacionais pelo poder público, porém com o achatamento dos custos empregados, colocando em risco a tão propalada qualidade (OLIVEIRA, 2001, p.109).
\end{abstract}

A análise das tendências pedagógicas no Brasil, principalmente a partir das transformações introduzidas pela Lei Federal 9394/96 deixa evidente a influência dos grandes movimentos educacionais internacionais, da mesma forma que expressam as especificidades da história política, social e cultural desse país, a cada período em que são consideradas. Atualmente podem ser claramente identificadas, tanto em nível de políticas educacionais como em nível de estabelecimentos de ensino, manifestando-se com maior ou menor intensidade, dependendo das intenções educativas dos agentes envolvidos.

A partir de 1988, com a promulgação da atual Constituição Brasileira, a Educação Básica passou a compreender desde a Educação Infantil, o Ensino Fundamental e até o Ensino Médio. Nesse sentido, a Lei 9394/96, que regulamenta a matéria, tem a flexibilidade característica principal. No entanto, as transformações introduzidas pela referida Lei, não resolve o problema da educação no Brasil, pois ao mesmo tempo em que permite a flexibilidade, no que se refere à classificação e reclassificação de alunos em ano/série/ciclo - tendo como parâmetro a relação idade e série; explicitando o papel da família, da escola e do educador; e possibilitando a cada Unidade Escolar construir o seu projeto político pedagógico - não traz ações efetivas que garantam a qualidade, uma vez que as políticas públicas de formação permanente do profissional de educação e a melhoria das condições de aprendizagem dos alunos não saem do plano da Lei. 
Com a possibilidade da progressão continuada, com a formação de Ciclos, mascarou-se uma situação de descaso das administrações públicas, pois a comunidade escolar não foi preparada para atuar dentro dessa nova perspectiva, gerando um desconforto entre os educadores, pais e estudantes, assim como provocando um grande descompasso entre o ensino e a aprendizagem. Assim sendo, a escola não vem respondendo as reais demandas educacionais. Rodrigues (1999) chama a atenção para esta questão:

\begin{abstract}
A educação foi confinada ao espaço e tempo escolares e estes aos interesses privados do mercado. Na escola, como no mercado, tudo se torna provisório, sucessivo, fragmentado, útil ou inútil conforme os interesses que vão definindo o desdobrar de suas atividades. Prédios e pessoas, equipamentos e conteúdos, métodos e valores são dissolvidos e reificados segundo propósitos momentâneos. O passado se reduz a abandono, o futuro a incertezas e o presente erigido em única força motriz do mundo. A escola deixa de ser um espaço e tempo de formação humana para se converter em lugar e tempo de fixação de destinos individuais. A escola passa a ter missão, atribuída de fora. Se lhe anunciam princípios de autonomia, estes não trazem em si qualquer significado, pois não guardam relação com o seu fim, apenas com os seus meios (RODRIGUES, 1999, p. 29-30).
\end{abstract}

Nesse sentido, é preciso dar um real significado a escola para que efetivamente ela exerça sua função social, e esse equilíbrio será materializado a partir do momento em que o educador seja valorizado, principalmente no que se refere a sua formação. Por isso, cada educador, ao adentrar o espaço de sua ação educativa, deve lembrar que, acima de tudo, está ali para a formação da pessoa humana em sua totalidade.

Vale registrar que a valorização do magistério, quer seja em condições de trabalho, quer seja em termos de salário, ou mesmo em relação à formação permanente dos educadores, não aconteceu, refletindo diretamente na qualidade da educação. Hoje, o Brasil não precisa fazer festa pela inauguração da Escola, contudo é preciso refletir, analisar e repensar as condições em que o aluno se forma.

Nesse contexto é preciso refletir sobre a identidade do educador enquanto profissional, porém, acima de tudo como ser humano, pois não é possível separar a atividade laborativa do jeito de ser de cada um, com suas características individuais que, embora atue num coletivo possui suas especificidades. Acerca disso, Nóvoa (1992) afirma:

Não é possível separar o eu pessoal do eu profissional, sobretudo numa profissão fortemente impregnada de valores e ideais [...] Ser professor obriga a opções constantes, que cruzam a nossa maneira de ser com a nossa maneira de ensinar (NÓVOA, 1992, p. 7-9). 
Diante disso, não há dúvida de que o papel do educador é de fundamental importância na formação do cidadão. No entanto, há de se considerar que este, tem que refletir incessantemente sobre a sua prática, pois ela implica diretamente na formação do outro. Para tanto, faz-se necessário que o professor se aproprie de múltiplos saberes e compreenda as transformações aceleradas por que passa a sociedade contemporânea, no sentido de construir sua identidade. E mais uma vez Nóvoa (1992) que chama a atenção para esta questão ao reiterar: "A identidade não é um dado adquirido, não é uma propriedade, não é um produto. A identidade é um lugar de lutas e conflitos, é um espaço de construção de maneiras de ser e de estar na profissão" (NÓVOA, 1992, p.1).

Nesse sentido, é preciso que o professor em sua atividade profissional transcenda o ato de ensinar conteúdos conceituais, atitudinais e procedimentais e atue em outro patamar o de educador, que tem uma função eminentemente política.

Cabe aqui, o registro do legado de Gramsci (1978b) ao afirmar que a transformação da sociedade somente será possível de forma efetiva, se esta estiver articulada com uma "reforma intelectual e moral" (GRAMSCI, 1978b, p.8-9), capaz de promover a transformação da sociedade, democratizando as oportunidades de forma igualitária.

Isso significa que,

\begin{abstract}
$\mathrm{Na}$ escola a consciência crítica e transformadora dos educandos só pode dar-se a partir da apropriação de uma visão de mundo elaborada que esteja comprometida com a construção de uma nova ordem social, ou seja, a partir da apropriação de uma nova ideologia, no sentido em que esta é dada pelo próprio Gramsci, como 'uma concepção do mundo que se manifesta implicitamente na arte, no direito, na atividade econômica, em todas as manifestações de vida individuais e coletivas (GRAMSCI, 1978a apud PARO 2001, p.42).
\end{abstract}

É nesse universo, que a escola e todos os sujeitos envolvidos no processo ensino e aprendizagem precisam atuar, ou seja, garantir espaço para que o conjunto da comunidade educativa possa elaborar e reelaborar suas ideias a partir de uma leitura de mundo que propicie estreita relação entre o texto e o contexto.

\title{
A FUNÇÃO SOCIAL DA ESCOLA
}

A alta complexidade dos problemas que envolvem o cotidiano da escola e sua função social, as transformações de valores, culturas e saberes que se processam cada vez mais rapidamente, o grau de incerteza global por que passa a sociedade contemporânea, exigem esforço 
intelectual e mental de todos aqueles que estão direta ou indiretamente envolvidos com a questão da educação e do conhecimento. Nas palavras de Greco (1996):

[...] Hoje, tão importante quanto o resultado específico do conhecimento que se adquire é a percepção do seu alcance, das suas intercorrências e, sobretudo, das suas consequências. E isso transcende o limite restrito das ciências, encontrando interfaces óbvias com outros níveis de conhecimento. Sobretudo para aqueles que se empenham nas atividades em que é fundamental a produção de bens simbólicos, como os constituintes do processo de mediação social, faz-se mister a busca de um novo paradigma para a abordagem da realidade - "um conhecimento do conhecimento" como denominou Edgar Morin, onde a ciência tenha um papel integrado com os demais níveis do saber e não uma supremacia como queria Comte com sua "lei dos três Estados". Um papel de interação e não de superioridade (GRECO, 1996, p 56).

Portanto, faz-se necessário repensar a função social da escola, uma vez que ela enfrenta o desafio de atender as novas exigências educacionais, resultantes dos avanços tecnológicos e da necessidade de superar desigualdades educacionais decorrentes de um processo de exclusão de ordem econômica e social, resultante do modelo econômico adotado na América Latina, em especial o Brasil neste estudo.

Nesse contexto, apontamos na literatura especializada as ideias de Pimenta (1998) quando afirma que:

A tarefa da escola é inserir as crianças e jovens tanto no avanço como na problemática do mundo de hoje, através da reflexão, do conhecimento, da análise, da compreensão, da contextualização, do desenvolvimento de habilidades e de atitudes. A identidade da escola nesse processo é garantir que as crianças e jovens sejam capazes de pensar e gestar soluções para que se apropriem da riqueza da civilização e dos problemas que essa mesma civilização produziu. É nessa contradição que se define a identidade da escola hoje (PIMENTA, 1998, p.50).

Ademais, comungamos com Pimenta (1998) ao escrever sobre o papel do conhecimento e como este é encarado pela sociedade nessa teia de relações:

Conhecimento não se reduz a informação. Esta é um primeiro estágio daquele. Conhecer implica, em um segundo estágio, de trabalhar com as informações classificando-as, analisando-as e contextualizando-as. O terceiro estágio tem a ver com a inteligência, a consciência ou sabedoria. Inteligência tem a ver com a arte de vincular conhecimento de maneira útil e pertinente, isto é, de produzir novas formas de progresso e desenvolvimento. Consciência e sabedoria envolvem reflexão, isto é, capacidade de produzir novas formas de existência, de humanização. Eé nessa trama que se pode entender as relações entre conhecimento e poder (op. cit. p. 52). 
Tal contribuição nos remete a reflexão sobre como a escola tem se colocado como prestadora de serviço ao cidadão. Esta exerce sua função verdadeiramente quando possibilita uma formação integral, atuando como lócus de construção do conhecimento, envolvendo os atores sociais num processo de ação-reflexão-ação, possibilitando através das múltiplas linguagens e dos diversos saberes, uma aprendizagem significativa na qual, através da dialética, seja possível estabelecer relações entre o texto e o contexto.

Nesse sentido, cabe destacar uma das ideias de Freire (1997, p.74): "Sabemos que não é a educação que modela a sociedade, mas, ao contrário, a sociedade é que modela a educação segundo os interesses dos que detêm o poder”. Portanto, é necessário resgatar a função social da escola no sentido de redesenhar seu papel como polo de produção de cultura e espaço democrático, no qual o estudante possa verdadeiramente formar-se para a autonomia e para o exercício pleno da cidadania.

O espaço da escola como lócus de produção de cultura, significa construir conhecimento além dos conteúdos historicamente acumulados, formando o cidadão para a inclusão social e não apenas para o mercado de trabalho, exige um esforço de todos os envolvidos com a educação, no sentido de considerar os aspectos que envolvem o cotidiano da escola e do estudante, desde as questões sociais, políticas e econômicas, perpassando pelos aspectos culturais e principalmente pela trama das relações existentes no interior da escola e seu entorno.

Para a escola exercer sua função social, deve ser pensada pelo conjunto dos atores envolvidos no processo, garantindo uma estreita relação entre teoria e prática, no sentido de buscar no processo ensino e aprendizagem uma articulação entre o senso comum e o conhecimento historicamente acumulado, com um ensino contextualizado que represente ao aluno não somente um ambiente para receber informações, mas especialmente para exercer seu poder de criação, que reflita numa aprendizagem significativa capaz de desenvolver seu pensamento crítico e reflexivo.

Sobre o pensamento crítico, Arroyo (1999) atesta:

O pensamento crítico toma como seu objeto os elementos constantes das estruturas, das instituições se dos processos globais, sociais, ideológicos e políticos, o que é legítimo e necessário para a compreensão dos fenômenos sociais, educacionais e culturais. Porém, essa mesma ênfase pode levar, e por vezes tem levado, à marginalização da concretude da prática social e educativa". (ARROYO, 1999, p. 144).

Nesses termos, faz-se necessário compreender as relações sociais existentes no interior da escola para que se possa verdadeiramente formar cidadãos críticos e conscientes de seu papel na sociedade. Paro (2001) chama a atenção para esta questão ao afirmar:

Com respeito às relações sociais escolares, ou às características sociais e políticas que assumem as práticas no interior da escola é preciso não 
ignorar, ao se refletir sobre políticas educacionais, que, embora produtos de determinações sociais mais amplas, as práticas escolares não deixam de ser configuradas também por condicionantes mais próximos e imediatos que não podem ser apreendidos sem se considerar a realidade concreta onde elas se manifestam (PARO, 2001, p.33).

Diante do exposto, é possível compreender que a relação pedagógica no interior da escola é de fundamental importância, sem a qual, o processo de ensino e aprendizagem fica fragmentado. Afinal, não se aprende de qualquer forma, sem uma ação reflexiva e sem a relação dialética. Não se aprende na perspectiva de construção da autonomia, sem apropriação do caminho que está trilhando, e cada sujeito trilha o seu caminho em ritmo distinto. Portanto, é necessário compreender os ritmos e espaços escolares de cada um, para que a escola assuma verdadeiramente sua função social.

Sendo assim, o grande desafio da escola em sua função social é possibilitar que as oportunidades educacionais sejam democratizadas de forma a contemplar toda a clientela, no sentido de formar para a cidadania, para a vida e para a inclusão social.

\section{CONSIDERAÇÕES FINAIS}

Foi assinalado no início deste trabalho que a preocupação fundamental seria a de analisar e entender o papel da educação na formação do cidadão para inclusão social em São Paulo a partir de 1980. A pesquisa propiciou uma série de reflexões que serão sucintamente elencadas nestas considerações finais.

Atualmente, o Sistema Educacional Brasileiro convive com o drama do analfabetismo, pois alunos que concluem o Ensino Fundamental, em sua grande maioria, saem pouco escolarizados. Muitas vezes, terminam o Ensino Médio sem saber ler e escrever corretamente.

Ademais, estamos vivendo a sociedade tecnológica calcada no conhecimento, ou simplesmente a sociedade do conhecimento. Portanto, faz-se necessário equipar o cidadão dos conhecimentos necessários para ocupação na atividade laborativa.

É neste universo que o discente vivencia situações diversificadas, favorecendo o aprendizado, para que ele possa aprender a aprender. Por muito tempo, a pedagogia focou o processo de ensino no professor, supondo que, como decorrência, estaria valorizando o conhecimento. O ensino, então, ganhou autonomia em relação à aprendizagem, criou seus próprios métodos e o processo de aprendizagem ficou relegado em segundo plano. Hoje é sabido que é preciso ressignificar a unidade entre aprendizagem e ensino, uma vez que, em última instância, sem aprendizagem o ensino não se consuma. 
Nesse sentido, é preciso repensar a formação permanente dos educadores, para acabar com a dicotomia discurso e prática. Por fim, cabe ressaltar que a educação no Brasil sempre funcionou como aparelho ideológico do Estado e como instrumento de contenção e liberação das tensões sociais, expulsando as camadas mais pobres para fora do muro da escola.

Parece claro que a formação propiciada no contexto escolar tem um duplo enfoque. Primeiro, não se pode deixar de conhecer a realidade social da atualidade, dos atuais conteúdos trabalhados nas escolas, das exigências atuais em termos de avaliação do conhecimento construído. Tudo isso necessita continuar sendo trabalhado. Segundo, no entanto, mais do que ensinado, deve ser repensado, analisado, discutido e ressignificado. Com um olhar nas demandas atuais e em um futuro próximo, cabe então o enfoque no ensino voltado ao ensinar a pensar, à análise crítica e ao desenvolvimento das capacidades mentais.

Indiscutivelmente, os estudantes de hoje, profissionais de amanhã, encontrarão problemas, fatos, conceitos, que nem imaginamos. Assim, é viável prepará-los para as novas realidades que estão postas. Isso ocorrerá se a escola do presente trabalhar com uma visão de futuro. Propiciar aos estudantes a conquista da autonomia, que não pode ser apenas um discurso, mas a mola mestra que impulsiona sua ação pedagógica.

\section{REFERÊNCIAS}

ARROYO, Miguel Gonzales. Administração e qualidade da prática educativa: exigências e perspectivas. Revista Brasileira de Administração da Educação. Brasília, v. 12, n. 1, p. 9-22, jan./jun., 1996.

BRASIL. Constituição da República Federal do Brasil. 1988.

Ministério de Educação e do Desporto. Lei no 9.394/96 de 20/12/1996.

DOURADO, Luiz Fernandes. A Reforma do Estado e as Políticas de Formação de Professores nos anos 1990. In: Dourado, Luiz Fernandes; Paro, Vitor Henrique (Orgs.). Políticas Públicas \& Educação Básica. São Paulo: Xamã, 2001.

FREIRE, Paulo. Política e Educação. São Paulo: Cortez, 1997.

FRIGOTTO, Gaudêncio (Org.). Educação e Crise do Trabalho: perspectivas de final de século. Petrópolis: Vozes, 1998.

GRAMSCI, Antonio. Concepção Dialética da História. 2. ed. Rio de Janeiro: Civilização Brasileira, 1978a.

. Concepção Dialética da História. 3. ed. Rio de Janeiro: Civilização Brasileira, 1978b. 
GRECO, Milton. Caminhos para a construção de um Saber Plural. In: MEDINA, Cremilda; GRECO, M. (Orgs.). Agonia do Leviatã: a Crise do Estado Moderno. São Paulo: ECA/USP/CNPq, 1996.

NÓVOA, António (Org.). Vidas de Professores. Porto: Editora, 1992. .(Coord.). As organizações escolares em análise. Lisboa: Dom Quixote, 1992.

OLIVEIRA, Dalila Andrade. Política Educacional nos Anos 1990: Educação Básica e Empregabilidade. In: Dourado, Luiz Fernandes; Paro, Vitor Henrique (Orgs.). Políticas Públicas \& Educação Básica. São Paulo: Xamã, 2001.

PARO, Vitor Henrique. Políticas Educacionais: Considerações sobre o discurso genérico e a abstração da realidade. In: Dourado, Luiz Fernandes; Paro, Vitor Henrique (Orgs.). Políticas Públicas \& Educação Básica. São Paulo: Xamã, 2001.

PIMENTA, Selma Garrido. Projeto Pedagógico e identidade da escola. Revista Educação e Formação, Taubaté, 1998. 